доцент, кандидат философских наук, Севастопольский государственный университет ул. Университетская, 33, г. Севастополь, 299053, Россия. Электронный адрес: sonia5@ ya.ru

\begin{abstract}
Аннотация. В статье рассматривается процесс диффузии ценностей коренных малочисленных народов Севера в процессе конфликта арктической цивилизации и западной техногенной цивилизации. Социологический анализ ценностей, проведенной по шкале Ш. Шварца показывает, что среди молодых аборигенов в значительной степени сохраняется этнически обусловленная иерархия ценностей, в структуру которых диффундируют ценностные представления новой для них социальной среды. Традиционные религии, к которым относятся автохтонные верования и православие, в результат диффузии ценностей вытесняются.

Ключевые слова: коренные малочисленные народы Севера, ценности, диффузия ценностей, культура, конфликт ценностей; религия.

\section{S.V. Pospelova, \\ VALUE DIFFUSION INDIGENOUS PEOPLES OF THE NORTH AND NON-INDIGENOUS POPULATION}

Associate Professor, $\mathrm{PhD}$ in Philosophy, Sevastopol State University

33, Universitetskaya str., Sevastopol, 299053, Russia, E-mail: sonia5@ya.ru

\begin{abstract}
The article deals with the process of diffusion of the indigenous peoples of values in the process of conflict Arctic civilization and Western industrial civilization. Sociological analysis of values drawn on a scale of Schwartz suggests that among young Aboriginal people is largely retained ethnically caused the hierarchy of values, in which the structure of the diffuse value for their presentation of the new social environment. Traditional religion, which includes indigenous beliefs and Christianity, the result of diffusion of the values are displaced.
\end{abstract}

Keywords: Indigenous People; values; the diffusion of values; culture; words tsennostey; Klyuchevye conflict; religion.

В настоящее время процесс диффузии культур продолжается ускоренным темпом и имеет четкую экономическую и геополитическую детерминацию. В отечественных социологических мониторингах анализ состояния и развития базовых ценностных представлений россиян под воздействием трансформационных процессов занимал и занимает важное место.

В качестве объекта социологических исследований чаще всего выступают ценностные ориентации личности или группы - выбор ценностей, производимый людьми. Они определяют избирательность отношения человека к материальным и духовным ценностям, которая проявляется в его поведении [4, с. 122].
Следует отметить, что эти процессы идут на фоне глобальных изменений ценностей человеческого общества, связанных с проявлениями критического состояния многих мировых мировоззренческих систем - западной и восточной цивилизаций.

Многообразие конкретно-исторических ценностных систем ставит вопрос об их типологизации. В данное время существуют различные точки зрения на эту проблему, среди которых следует выделить формационный и цивилизационный подходы. Формащионный подход характеризуется соотнесением типов ценностных систем с этапами развития человечества или с типами общественноэкономических формаций, как это принято в марксисткой теории ценностей и решает задачу определения основных, преимущественно 
экономических ценностей различных обществ. Но тщательное исследование культуры различных обществ в один и тот же временной период показывает, что наряду с общими основными элементами их ценностных систем наблюдаются и значительные различия некоторых других ценностей. Так система ценностей средневековых феодальных обществ Европы с трудом может сопоставлена с ценностями феодального Востока. Более того, формационных подход ставит разные культуры в позицию подчиненности. Культуры тралицонные, рассматриваются как дикарство и варварство. Культуры более «высоких» формаций является приоритетными. В связи с этим заслуживает внимания исследование ценностных систем с позиций их цивилизационной принадлежности.

Цивилизационный подход используется в тех случаях, когда системы ценностей рассматриваются в связи с их принадлежностью к существовавшим и существующим конкретным цивилизациям. Сторонники данной методологии говорят о «восточной» и «западной» цивилизациях, «традиционных» и «техногенных», «домашней» и «рыночной». В основу определения культуры западной и восточной цивилизации Ф. Нортроп [5] положил различия в способах познания мира в восточных и западных культурах. Восточное миропостижение имеет интуитивный характер, что способствует развитию описательных наук и импрессионистского искусства. Время, природа, история воспринимаются как замкнутый цикл. Иерархическая модель семейных отношений переносится на социальную сферу. Власть персонифицируется и обожествляется. Свобода личности трактуется как уход во внутренние пространства души. Техническое развитие общества не носит характер приоритетной ценности.

Определение основных ценностей восточных и западных обществ было целью большого кросскультурного исследования, проводившегося сотрудниками американских университетов и направленного на выявление особенностей мировосприятия в различны современных обществах [6]. Задачи исследования включали изучение и классификацию ценностей различных культур. Типологизация ценностей была проведена по двум основаниям: по значению ценности и по локальной принадлежности к культуре. По результатам исследования система ценностей западных обществ характеризуется присутствием в ней в качестве первичных следующих ценностей: индивидуальность, иерархия, деньги, пунктуальность, спасение, первенство, агрессивность, уважение к молодежи, цвет кожи, равенство женщин, человеческое достоинство, эффективность, религия, образование, непосредственность. Первичные ценности восточной системы представляют: материнство, иерархия, мужественность, мощь, мир, скромность, карма, коллективная ответственность, уважение к старшим, гостеприимство, наследуемое имущество, сохранение Среды, цвет кожи, святость пахотной земли, патриотизм, религия, авторитаризм.

Ценности Восточной цивилизации лежат в основе культуры «традиционных» обществ [9].

Коренные малочисленные народы Севера как особый тип социума, как специфичный субъект хозяйственной деятельности являются носителями традиционного хозяйственного уклада жизни и культуры, адаптированного к природной и ресурсной среде Севера, представителями особого пути эволюции человека - особой арктической цивилизации, формирование которой происходило в течение тысячелетий. Одним из важнейших условий сохранения и дальнейшего развития культуры коренных малочисленных народов Севера является признание ценности и уникальности их культуры, прежде всего, ими самими, что, в свою очередь, служит основой сохранения национального самосознания.

Следовательно, сложившаяся социальная ситуация предполагает социологическое исследование населения из числа коренных малочисленных народов Севера как социального субъекта и соответствующей ему деятельности, обусловленной специфической системой ценностей, которая в результате социальных процессов, происходящих в регионе, наполняется иным содержанием. В результате совершается интенсивное изменение мотивации на деятельность в сфере общественной жизни, ценностного отношения к общественной деятельности, ее соотношения с другими видами деятельности.

Модернизационные процессы ставят новые задачи перед социологами в области исследования системы ценностных ориентаций коренных малочисленных народов Севера. 
Необходим целостный социокультурный анализ, позволяющий определить место и роль образования и социокультурной деятельности образования в процессах взаимодействия культуры и общественных реформ, социальной дифференциации, а также воздействия новых социальных ценностей на феномены духовной жизни коренных малочисленных народов Севера.

Для исследования ценностей имеется широкий спектр методик, выбор которых определяется особенностями каждой выделенной ценности и ее местом в системе ценностей. Однако существует ограничение, связанное с реальными возможностями исследователя, и эти ограничения, к сожалению, неизбежны при обращении к каждой из выделенных проблем.

Примером адаптации цели исследования ценностей аборигенов к реальной возможности практической реализации (при условии одного исполнителя) может служить их описание в контексте выполненного в г. Магадане анализа ценностных ориентаций молодежи (учащиеся) и жителей-аборигенов представительной выборки коренного населения, проживающего в Магаданской области в 2004 и в 2011 гг. $[3 ; 7 ; 8]$.

В процессе долгой совместной жизнедеятельности людей в рамках каждой этнической группы вырабатывались общие и устойчивые признаки, отличающие одну этническую группу от другой. К числу таких признаков относятся язык, особенности бытовой культуры, складывающиеся обычаи и традиции того или иного народа или этноса (в различных языках и в научной литературе термины «народ» и «этнос» употребляются как синонимы). Эти признаки воспроизводятся в этническом самосознании народа, в котором он осознает свое единство, прежде всего общность своего происхождения и тем самым свое этническое родство. В то же время он отличает себя от других народов, которым свойственно свое происхождение, свой язык и своя культура. Этническое самосознание народа рано или поздно проявляется во всем его самосознании, в котором фиксируется его происхождение, унаследованные традиции, понимание им своего места среди других народов. Проведенное исследование также направлено на анализ как общих, так и этнических критериев в системе ценностей учащейся молодежи коренных малочисленных народов Севера. Исследования проводились на основе методики диагностики ценностей «Изучение ценностей личности», широко использующаяся в нашей стране в последние десятилетия, разработанной Шаломом Шварцем па основе методики М. Рокича и его концепции о существовании терминальных и инструментальных ценностей [10]. Как известно, теоретической основой методики Шварца стала его концепция о мотивационной цели ценностных ориентации и универсальности базовых человеческих ценностей (витальные, социальные, политические, моральные, религиозные, эстетические).

Для выяснения предпочтений системы ценностей по шкале можно наглядно просмотреть, каким жизненным ценностям отдают предпочтения все респонденты учащиеся из числа коренных малочисленных народов Севера по сводному частотному распределению каждого из массивов данных учащихся. В сводной таблице распределения по всему массиву по предпочитаемой позиции распределились следующим образом ${ }^{1}$ (табл. 1).

Очевидно, что этнические критерии как «национальная гордость», «принадлежность к своему народу», включенные методику опроса, в иерархии шкалы ценностей у респондентовшкольников отсутствуют, что свидетельствует об уходе на второй план представлений о значении национальной идентичности в обследованной группе школьников.

Респонденты-студенты училища критерий «национальная гордость» реализовали лишь на восьмой позиции, а этнический критерий «принадлежность к своему народу» не распознали.

Респонденты-студенты Вузов этнический фактор «принадлежность к своему народу» предъявили лишь на девятой позиции, а критерий «национальная гордость» не выделили.

Анализ данных показывает отсутствие этнических категорий среди ценностей в возрасте от 14 лет до 20 лет, а к 20-25 годам эти ценности появляются на последних позициях.

${ }^{1}$ Номера позиций, занимаемых отдельными ценностями в каждой группе. 
Жизненные ценности респондентов

Таблицча 1

Behaviour of respondents

Table 1

\begin{tabular}{|c|c|c|c|c|}
\hline \multirow[b]{2}{*}{ № } & \multicolumn{4}{|c|}{ Жизненные ценности } \\
\hline & Школьники & Студенты училища & $\begin{array}{c}\text { Слушатели } \\
\text { подготовительного } \\
\text { отделения }\end{array}$ & Студенты Вузов \\
\hline 1 & Здоровье & $\begin{array}{l}\text { Материальное } \\
\text { благосостояние }\end{array}$ & $\begin{array}{l}\text { Здоровье } \\
\text { Образование }\end{array}$ & Здоровье \\
\hline 2 & Образование & Здоровье & Счастливая семейная жизнь & Хорошие и верные друзья \\
\hline 3 & $\begin{array}{l}\text { Хорошие } \\
\text { друзья }\end{array}$ & Образование & Развитие способностей & $\begin{array}{l}\text { Счастливая семейная } \\
\text { жизнь }\end{array}$ \\
\hline 4 & $\begin{array}{l}\text { Счастливая семейная } \\
\text { жизнь }\end{array}$ & Творчество & Уверенность в себе & Любовь \\
\hline 5 & Самостоятельность & Самостоятельность & $\begin{array}{l}\text { Любовь } \\
\text { Самостоятельность }\end{array}$ & Развитие способностей \\
\hline 6 & Развитие способностей & $\begin{array}{l}\text { Успешная } \\
\text { профессиональная } \\
\text { деятельность }\end{array}$ & Хорошие и верные друзья & Самостоятельность \\
\hline 7 & Творчество & Уверенность в себе & $\begin{array}{l}\text { Успешная } \\
\text { профессиональная } \\
\text { деятельность }\end{array}$ & $\begin{array}{l}\text { Материальное } \\
\text { благосостояние }\end{array}$ \\
\hline 8 & $\begin{array}{l}\text { Успешная } \\
\text { профессиональная } \\
\text { деятельность }\end{array}$ & Национальная гордость & $\begin{array}{l}\text { Жизнь } \\
\text { удовольствия }\end{array}$ & Творчество \\
\hline 9 & $\begin{array}{l}\text { Общественное } \\
\text { признание }\end{array}$ & Развитие способностей & $\begin{array}{l}\text { Материальное } \\
\text { благосостояние }\end{array}$ & $\begin{array}{l}\text { Принадлежность } \\
\text { своему народу }\end{array}$ \\
\hline 10 & Любовь & Любовь & $\begin{array}{l}\text { Принадлежность к своему } \\
\text { народу }\end{array}$ & $\begin{array}{ll}\text { Жизнь } & \text { полная } \\
\text { удовольствий }\end{array}$ \\
\hline
\end{tabular}

Наиболее высоким рангом среди ценностей является виктимная ценность («Здоровье» (1 и 2 позиция). Можно предположить, что данный факт - закономерная реакция на острую современную проблему сложности адаптации молодежи к урбанистическим условиям жизни. В традиционной культуре потребность сохранения здоровья безусловно осознавалось, но не являлось доминантным перед проблемами жизнеобеспечения в экстремальных условиях Севера.

Ярким примером диффузии ценностей является позиция «Образование», занимающая одну из главных позиций. В традиционной культуре знания, умения и навыки в той или другой форме осознавались или фиксировались в мифологии как непременное условие, как предикат существования. По отношению к опрошенным группам молодым людям эта установка конкретизировалась под влиянием техногенной культуры.

Социальные ценности (коллективизма, группового единства, товарищеского взаимодействия), доминантные в традиционной культуре нашли свое отражение в позиции «Хорошие и верные друзья» не только среди школьников, но и во всех остальных группах молодежи. Это объясняется стойкостью и значением коллективизма как ценности для аборигенов Севера.

Не случайно в иерархии традиционных ценностей, отразившихся в результатах исследования, оказались представления о «Счастливой семейной жизни», а такая ценность как «Любовь» занимает достойное место среди традиционных ценностей, осознается всеми группами молодежи, но выходит на одно из первых мест лишь в старших группах.

Наибольший интерес в смысле сопоставления традиционных и европейских ценностей являются позиции, формирующие персональноое самосознания «Самостоятельность», «Уверенность в себе». Позиция этих ценностей противостоит новой, весторнизированной, гедонистической, индивидуалистической ценности как «Жизнь, полная удовольствия». Для аборигенов Севера гедонизм проявляется только в праздниках и других формах проведения свободного времени, но удовольствие, как таковое, явно не осознается как особо значимая ценность.

Традиционной ценностью для большинства молодежи коренных народностей Севера оказывается «Творчество», что отражает особенности менталитета и приверженность к красоте и образной выразительности не только 
для «Успешной профессиональной деятельности», но и всех других видов деятельности аборигенов Севера.

Интересно, что «Материальное благосостояние» как не традиционная ценность выходит на первый план для студентов профессионального училища. Среди школьников эта ценность не осознается, а у студентов не занимает ведущей позиции.

Оценивая приведенные выше данные в целом, можно утверждать, что среди молодых аборигенов в значительной степени сохраняется этнически обусловленная иерархия ценностей, в структуру которых диффундируют ценностные представления новой для них социальной среды.

Насколько на сохранение и диффузию ценностей влияет сохранение родного языка и отношение к овладению родным языком (в случае его утраты по тем или другим причинам)? Очевидно, что этот вопрос требует специального исследования. Это подтверждается тем фактом, что среди молодежи школьного возраста лишь 3, 4 \% считали, что «Владеют родным языком в совершенстве», $28,8 \%$ - «Понимали, но разговаривали на родном языке» и считали, что «Полностью не владеют родным языком» $-67,8 \%$ респондентов.

При анализе традиционных ценностей аборигенов Севера трудно оставаться на позициях «культурного традиционализма». Как и социокультурное развитие любых этносов в целом, ценностный аспект культуры детерминируется не только в духовной сфере, но и реальными условиями жизнедеятельности, то есть реалиями природной среды и использованием ее ресурсов в образе жизни и деятельности населения. Не смотря на доминирующий в культурологи подход к социально-культурному развитию, прежде всего, как к духовному развитию, трудно обойти такие понятия как материальная культура, образ жизни и жизнедеятельность, из которых последнее в наибольшей степени отражает биосоциальный характер основных движущих сил, определяющих воспроизводство и сохранение этносов - особенно в экстремальных природногеографических условиях.

Религия не вошла в десятку доминантных ценностей. Для уточнения предпочтений по этой позиции были проведены дополнительные исследовании. Студентам и учащимся было предложено ответить на вопросы «Считаете ли Вы себя верующим человеком?» и «Если Вы считаете себя верующим человеком, то к какому вероисповеданию Вы относитесь?» Анализ выявил следующую картину:
Таблициа 2

Религиозность и вероисповедание респондентов

Table 2

Religiosity and Religion respondents

\begin{tabular}{|l|c|}
\hline \multicolumn{1}{|c|}{ Варианты ответов } & $\%$ \\
\hline Не считаю себя верующим человеком & 32,9 \\
\hline $\begin{array}{l}\text { Считаю себя верующим, но не могу сказать } \\
\text { к какому вероисповеданию отношусь }\end{array}$ & 14,8 \\
\hline Православие & 46,7 \\
\hline Евангельские христиане-пятидесятники & 2,4 \\
\hline Традиционные верования (шаманисты) & 3 \\
\hline
\end{tabular}

Данные распределения обусловлены тем, что опрос проводился среди студентов и учащихся, которые преимущественно проживают в национальном районе, где зарегистрированы две религиозные организации: православие и евангельские христиане пятидесятники. Русская православная церковь в регионе имеет значительную долю приверженцев, признающих ее особую роль и традиционный характер. Эвены массово стали принимать христианство с 1780-х гг. К 1820 г. практически все они были уже крещены (по сведениям святителя Иннокентия (Вениаминова), в то время епископа Камчатского, Курильского и Алеутского) [1]. Это подтверждается и свидетельством священника Андрея Аргентова, который указывал, что среди колымских эвенов «язычники вывелись» уже в начале XIX в. [2]. Эвены стали одним из наиболее христианизированных народов Севера. В местах их расселения строились православные церкви и часовни. Христианство охватывало практически все стороны жизни эвенов. Рождение, брак, смерть, бытовое поведение, исполнение обрядов и праздников, все регулировалось православной традицией. В меньшей мере, но такая же картина распространения православия наблюдалась и у коряков Магаданской области. Традиционные верования фактически «вернулись» в регион последние 10 лет. Праздники природных циклов, поклонения «семейным» духам, «жертвоприношения» домашним идолам сегодня определенная часть КМНС рассматривает как «возвращение к национальным истокам». В тоже время нельзя не отметить деятельность различных протестантских деноминаций, активизировавшихся в области. В национальных районах области случаях рост последователей протестантских конфессий из числа КМНС достигает до 50 процентов в маленьких национальных селах и поселках. Например, в национальном селе Верхний Парень.

На вопрос: Стремитесь ли Вы ориентироваться на религиозные ценности В 
Вашей повседневной жизни? (соблюдаете правила и запреты, определенные Вашей религией) были получены следующие ответы:

Таблииа 3

Стремление респондентов ориентироваться на религиозные ценности в повседневной жизни

Table 3

The desire of the respondents rely on religious values in daily life

\begin{tabular}{|l|c|c|c|c|}
\hline \multicolumn{1}{|c|}{ Варианты ответов } & $\begin{array}{c}\text { Да, я всегда } \\
\text { ориентируюсь на } \\
\text { религиозные ценности }\end{array}$ & $\begin{array}{c}\text { Я ориентируюсь на } \\
\text { религиозные ценности в } \\
\text { зависимости от ситуации }\end{array}$ & $\begin{array}{c}\text { Нет, я никогда не } \\
\text { ориентируюсь } \\
\text { нелигиозные ценности }\end{array}$ & 30 \\
\hline $\begin{array}{l}\text { Евангельские христиане } \\
\text { пятидесятники }\end{array}$ & $100,0 \%$ & $67,1 \%$ & $12,9 \%$ & $10,7 \%$ \\
\hline Православие & $9,3 \%$ & $55,8 \%$ & $5,5 \%$ & $30,2 \%$ \\
\hline $\begin{array}{l}\text { Традиционные верования } \\
\text { (шаманисты) }\end{array}$ & $1,3 \%$ & & & 30 \\
\hline
\end{tabular}

Евангельские христиане пятидесятники появились в национальном районе только в 2000 году и в результате активной миссионерской работы создали религиозную организацию только из аборигенов.

Очевидно, что ценности «новой» для молодежи КМНС религии являются доминантными и вытесняют традиционные ценности.

Диффузия ценностей имеет серьезный, предопределенный историческим развитием цивилизационный аспект. Именно «внутри» цивилизации оказываются возможными те или другие формы межэтнического взаимодействия во всех его проявлениях.

\section{Литература}

1. Афанасьева Н.Р. Эвены и христианство. Записки Гродековского музея. 2007. Вып. 18. Культура народов Дальнего Востока URL: http://pravostok.ru/blog/eveni-i-hristianstvo/

2. Эвены. Этнонациональные общности России. URL: //http://www.ethnos.nw.ru/lib/data/142.html

3. Громова Н.3. Особенности ценностных ориентаций на образование у коренных малочисленных народов Севера: дис. ... канд. социол. наук. М., 2005. 173 с.

4. Козлова О.Н. Духовная культура современного общества // Социально-политич. науки. 1991. №10.

5. Орлова Э.А. Введение в социальную и культурную антропологию. М., 1994.

6. Ситарам К.С., Когделл Р.Р. Основы межкультурной коммуникации // Человек. 1992. №2. C. 51-64; №3. C. 60-68; №4. C. 106-116.

7. Поспелова С.В. Отношение к религии и ценностные ориентации жителей Магаданской области: дис. ... канд. филос. наук. М., 2005. 173 с.

8. Поспелова С.В. Религия и ценностные ориентации жителей магаданской области / Социология религии в обществе Позднего Модерна (памяти Ю.Ю. Синелиной): материалы Третьей Международной научной конференции. НИУ «БелГУ», 13 сентября 2013 г. / отв. ред. С.Д. Лебедев. Белгород: ИД «Белгород», 2013. С. 299.

9. Ценности техногенной цивилизации // Вопросы философии. 1994. №6. С. 10-22.

10. Shalom H. Schwartz. An Overview of the Schwartz Theory of Basic Values // Online Readings in Psychology and Culture. 2012. 2(1). Pp. 45-56.

\section{References}

1. Afanas'eva N.R. Evens and Christianity. Note Grodekovsk Museum. 2007. Vol. 18. The culture of the peoples of the Far East. URL: http://pravostok.ru/blog/eveni-i-hristianstvo/

2. Evens. Ethno-national community of Russia. URL: //http://www.ethnos.nw.ru/lib/data/142.html

3. Gromova N.Z. Peculiarities of value orientations to education in the indigenous peoples of the North: dis. kand. of sociological sciences. Moscow, 2005. 173 p.

4. Kozlova O.N. The spiritual culture of modern society. Socio-political sciences. 1991. No. 10.

5. Orlova E.A. Introduction to social and cultural anthropology. Moscow, 1994.

6. Seetharam K.S., Cogdell R.R. Foundations of intercultural communication. Human. 1992. No. 2. Pp. 51-64; No. 3. Pp. 60-68; No. 4. Pp. 106-116.

7. Pospelova S.V. the Relation of religion and value orientation of the inhabitants of the Magadan region: dis. kand. of philosophical sciences. Moscow, 2005. 173 p.

8. Pospelova S.V. Religion and value orientation of the inhabitants of the Magadan region. Sociology of religion in Late Modernity (memory Y.Y. Sinelina): proceedings of the Third International scientific conference. BSU. Belgorod: publishing house «Belgorod», 2013. P. 299.

9. Values of technogenic civilization. Problems of philosophy. 1994. No. 6. Pp. 10-22.

10. Shalom H. Schwartz. An Overview of the Schwartz Theory of Basic Values. Online Readings in Psychology and Culture. 2012. 2(1). Pp. 45-56. 